\title{
CLINICAL INERTIA IN TYPE 2 DIABETES MELLITUS WITHOUT INSULIN TREATMENT
}

J.Nunes e Silva, C. Ivo, L. Lopes, H. Simões, D. Passos, M. Marcelino, J. Jácome de Castro

Endocrinology, Diabetes and Metabolism Department, Portuguese Armed Forces University Hospital

\section{Introduction}

Clinical inertia applied to type2 Diabetes Mellitus (T2DM) treatment, is defined as a lack of treatment's intensification of patients who aren't in HbA1c target. Clinical inertia leads to a postponement of new therapeutic introduction, with all complications associated with a poor metabolic control. In Portugal there are only studies that show good or poor metabolic control but don't mention clinician's attitude towards these values. Recently published international studies reveal partial clinical inertia in $52.5 \%$ of cases and full clinical inertia in $12.8 \%$.

\section{Objective}

To evaluate clinical inertia of T2DM's treatment in an Endocrinology department

\section{Methods}

Cross-sectional, retrospective study of a random sample of patients with non-insulin treated T2DM, with minimum 12 months follow-up, during 2014 . 2015. It was established individualized HbA1c target based on patients' characteristics: life expectancy, hypoglycemia, cardiovascular disease or other comorbidities. Total clinical inertia was defined as no treatment's intensification at every visit and partial clinical inertia in at least one visit.

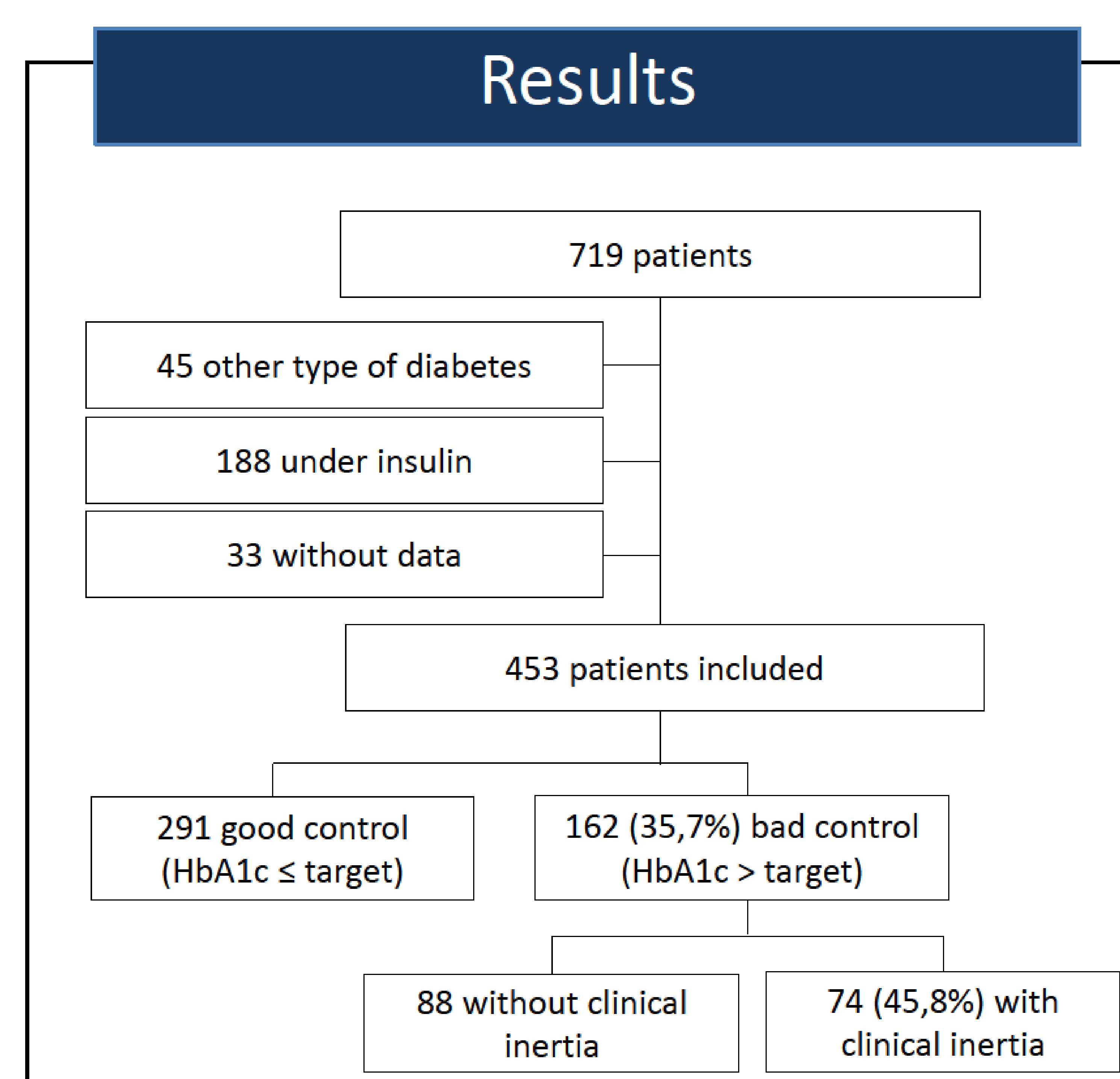

Figure 1: Patients with good and bad metabolic control and with or without clinical inertia

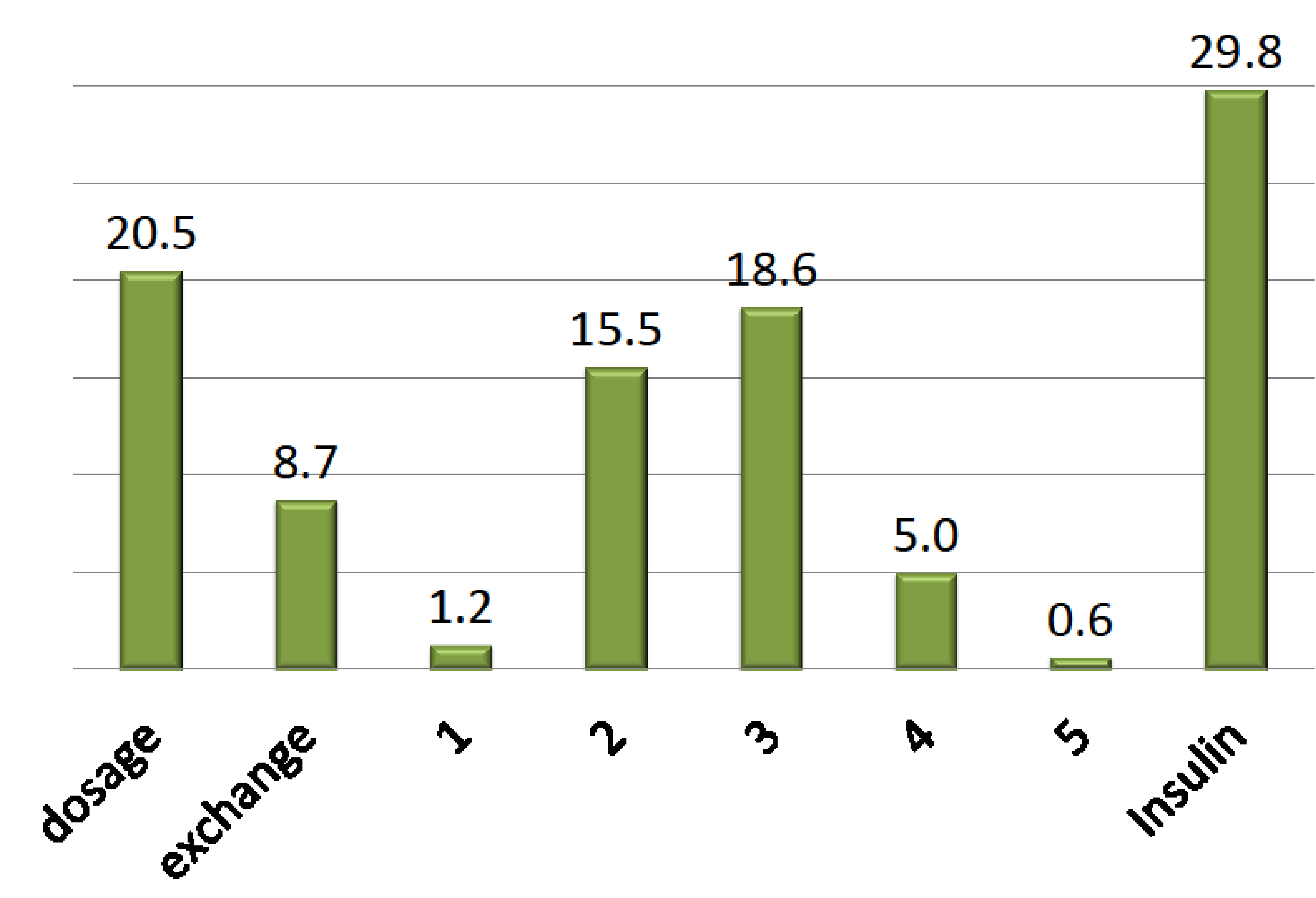

Figure 2: Types of treatment intensification

\begin{tabular}{|c|c|c|c|c|c|}
\hline & $\begin{array}{c}\text { Total } \\
(n=453)\end{array}$ & $\begin{array}{c}\text { Good } \\
\text { control } \\
(n=291)\end{array}$ & $\begin{array}{l}\text { Bad control } \\
(n=162)\end{array}$ & $\begin{array}{l}\text { Without } \\
\text { inertia } \\
(\mathbf{n}=\mathbf{8 8})\end{array}$ & $\begin{array}{l}\text { With } \\
\text { inertia } \\
(n=74)\end{array}$ \\
\hline $\begin{array}{c}\text { Sex: Male. } \\
\text { n (\%) }\end{array}$ & $329(72.6)$ & $214(73.3)$ & $115(70.6)$ & $60(68.2)$ & $55(74.3)$ \\
\hline Age (Years) & $68.6 \pm 10.1$ & $69.8 \pm 10.4$ & $66.1 \pm 10.5$ & $\begin{array}{c}65.1 \pm \\
13.3\end{array}$ & $66.3 \pm 9.8$ \\
\hline $\begin{array}{l}\text { T2DM duration } \\
\text { (years) }\end{array}$ & $12.1 \pm 11.2$ & $11.5 \pm 11.5$ & $13.2 \pm 10.7$ & $\begin{array}{c}12.7 \pm \\
11.6\end{array}$ & $13.7 \pm 9.4$ \\
\hline \multicolumn{6}{|l|}{$\begin{array}{l}\text { HbA1c target } \\
(\mathrm{n}(\%))\end{array}$} \\
\hline$\leq 7 \%$ & 281 (61.6) & $170(58.4)$ & 111 (68.5) & 59 (67.0) & $52(70.3)$ \\
\hline $7-7,5 \%$ & $146(32.2)$ & $100(34.2)$ & $46(28.4)$ & $26(29.5)$ & $20(27)$ \\
\hline $7,5-8 \%$ & $26(5.7)$ & $21.0(7.2)$ & $5(3.1)$ & $3(3.4)$ & $2(2.7)$ \\
\hline \multicolumn{6}{|l|}{$\begin{array}{l}\text { Treatment } \\
(\mathrm{n}(\%))\end{array}$} \\
\hline 0 & $17(3.8)$ & $10(3.4)$ & $7(4.3)$ & $6(6.8)$ & 0 \\
\hline 1 & 149 (32.9) & $118(40.5)$ & $36(22.2)$ & $28(31.8)$ & $5(8.6)$ \\
\hline 2 & $178(39.3)$ & $109(37.5)$ & 65 (40.1) & $32(36.4)$ & $35(47.3)$ \\
\hline 3 & 97 (21.4) & $50(17.2)$ & $45(27.8)$ & $18(20.5)$ & $28(37.8)$ \\
\hline 4 & $12(2.6)$ & $2(0.7)$ & $9(5.6)$ & $4(4.5)$ & $6(8.1)$ \\
\hline $\begin{array}{l}\text { Follow-up } \\
\text { (months) }\end{array}$ & $15.8 \pm 6.1$ & $15.7 \pm 6.0$ & $14.9 \pm 6.6$ & $14.8 \pm 6.8$ & $16.3 \pm 6.3$ \\
\hline
\end{tabular}

Table 1: Patients characteristics

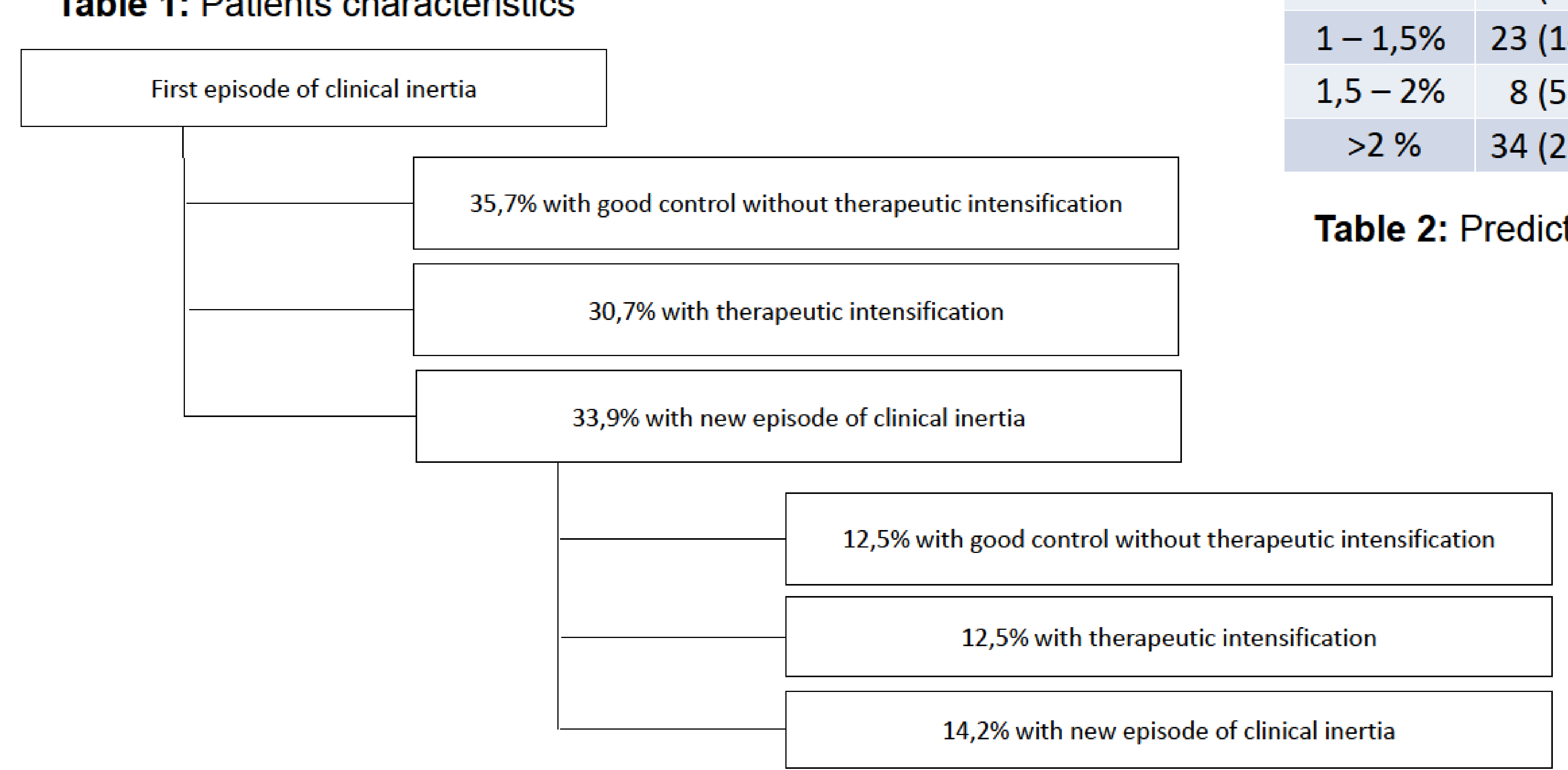

Figure 3: Follow up: second and third visit after a first episode of clinical inertia

\section{Discussion/Conclusion}

In our study, during 2 years $45,8 \%$ of the patients suffered at least one episode of clinical inertia. This is lower than Lin described in 2016 (70,4\%) or Gonzalez-Clemente in 2013 (52,5\%). The predictor factors of clinical inertia that we found out were the complexity of treatment and when patients were closer to their target HbA1c. Mata-Cases in 2013 also described that values close to target contribute to clinical inertia and Lin 2016 found that complexity of treatment was a predictor factor. We didn't found any association with age, gender or duration of T2DM. Gonzalez-clemente found that female and a short period of T2DM were predictors of clinical inertia and Lin associated with older patients. After follow-up in our series only $8,4 \%$ were still under clinical inertia, while the others authors described it between $12-50 \%$.

There is still time to improvement and knowing which factors contribute to clinical inertia is one way to fight it. 